DOI: $10.17805 /$ zpu.2015.4.27

\title{
Почему Друг Поэта должен жениться: переводческие толкования первых 17 сонетов Шекспира*
}

\author{
E. A. ПЕРВУШИНА \\ (ДАЛЬНЕВОСТОЧНЫЙ ФЕДЕРАЛЬНЫЙ УНИВЕРСИТЕТ)
}

Первые семнадцать сонетов в сборнике У. Шекспира, где главный герой восхищается своим красивым Другом и уговаривает его жениться, всегда привлекали внимание. В последние десятилетия, когда в России невероятно увеличилось количество синхронических переводов,

* Подготовлено при поддержке РГНФ (проект «В. Шекспир. Сонеты. Подготовка текстологического, историко-литературного и поэтологического комментария», грант № 14-04-00531).

The article was written within the framework of the project "Shakespeare's Sonnets. Textological, Historical, Literary and Poetological Commentary" (grant from the Russian Foundation for the $\mathrm{Hu}-$ manities, No. 14-04-00531). 
активизировались переводческие толкования указанной группы стихотворений. Цель данной статьи - представить наиболее значимые и интересные из таких толкований.

Один из лучших представителей отечественной школы поэтического перевода И. М. Ивановский увидел в первых семнадцати сонетах отражение страшной трагедии Шекспира, у которого в 1596 г. умер сын. Поэтому у Ивановского насыщенно экспрессивна и тревожна «поэтическая музыка» этой группы стихов.

Другой известный поэт-переводчик И. З. Фрадкин убежден в композиционной и поэтической целостности шекспировского сонетного свода. Эта уверенность просматривается даже в эдиционном структурировании последнего издания переводов Фрадкина, построенного по принципу развернутой сонетной композиции. Первые семнадцать стихотворений выполняют роль своеобразного зачина, где формулируется сонетный тезис. Здесь, по мнению Фрадкина, зарождаются циклообразующие лейтмотивы Смерти и Возрождения.

Особая творческая энергетика воплощена в имитативных переводческих вариациях на темы шекспировских сонетов. Они показывают возможности свободной игры художественными смыслами шекспировских стихов, открывая их новые смысловые проекции. Так, Ю. И. Лифшиц, восприняв в стихах Шекспира экспрессию диалога, вывел в своих поэтических вариациях новую героиню - одержимую страстью женщину, влюбленную в молодого красавца.

Рассмотренные переводческие трактовки - важный фактор в рецептивном созидании поэтического имиджа русского Шекспира.

Ключевые слова: Шекспир; сонеты Шекспира; русские переводы сонетов Шекспира

\section{ВВЕАЕНИЕ}

И 3 всех многочисленных загадок, уже четвертое столетие сопровождающих все связанное с именем У. Шекспира, одной из самых больших его тайн остаются «Сонеты», которые М. М. Морозов назвал задачей, состоящей из одних неизвестных (Морозов, 1954: 278). Неизвестно точное время создания этих стихов, хотя шекспироведы склонны датировать их 1592-1598 гг. Неизвестно, имеют ли «Сонеты»автобиографическую основу, были ли у героев цикла прототипы, кто эти прототипы и какие отношения связывали их с автором. Неизвестно, кто был составителем сборника «едва ли то был сам Шекспир», - считал А. А. Аникст (Аникст, 1963: 311). Неизвестно, является ли правильной та последовательность, в которой воспроизведены сонеты Шекспира в первом издании цикла, предпринятом в 1609 г. Т. Торпом (Shakespeares sonnets ..., 1609). Тем не менее в массовом читательском сознании сложилось кажущееся несомненным представление о «Сонетах» как о безусловно автобиографической сюжетно организованной лирической повести о привязанности главного героя - Поэта - к прекрасному юноше - Аругу - и о его страстной любви к очаровательной смуглой женщине - Ааме. В подобной сюжетной организации давно выделена группа первых семнадцати сонетов, в которых Поэт восхищается Аругом, призывая его жениться, чтобы продолжить в сыне свою красоту и свои достоинства.

Исследовательские комментарии этой тематической группы разнообразны и сложны. Признававшие автобиографизм сонетного свода Шекспира активно обсуждали предположение о том, что его вводная часть могла быть написана по заказу, тогда ее содержание определялось обстоятельствами жизни заказчика (об этом подробнее см.: Ауков, Флорова, 2009). Исследователи эстетической проблематики «Сонетов» сделали вывод о том, что именно в первых семнадцати стихотворениях задается философски глубокая тема красоты, органично связанная у Шекспира с идеей бессмертия. «Отражаемая в зеркале красота преходяща; отраженная в детях она бессмертна», - сказал А. А. Аникст, комментируя 3-й сонет (Аникст, 1984: 299).

В последние десятилетия в России невероятно увеличилось количество синхронических переводов, открывающих возможности беспредельной творческой игры 
в поэтическом пространстве сонетов Шекспира. В результате появились различные переводческие толкования первых семнадцати стихотворений и их места в общем своде. Изучение этих трактовок как важного акцентирующего фактора в рецептивном созидании поэтического имиджа русского Шекспира представляет несомненный научный интерес. Цель данной работы - не претендуя на исчерпывающий анализ, представить некоторые, на наш взгляд, особенно значимые и интересные из указанных толкований.

\section{ТРАКТОВКА И. М. ИВАНОВСКОГО}

В первую очередь, назовем одного из лучших представителей отечественной школы поэтического перевода Игнатия Михайловича Ивановского. Ученик М. А. Аозинского, рекомендованный в Союз писателей А. А. Ахматовой и С. Я. Маршаком, он автор многих произведений и переложений, в том числе уникальных стихотворных переложений полного текста Библии и фрагментов Священного Предания. Более всего Ивановский прославился переводами шведской поэзии, в связи с чем был удостоен премии Шведской академии и стал членом Бельмановского литературного общества Швеции. Однако его переводы с английского тоже очень известны. В начале 1960-х годов издательство «Аетгиз» выпустило книгу «Аерево свободы», в которую были включены стихи А. Китса, П. Б. Шелли, Аж. Г. Байрона, английские песни и баллады в переводах И. М. Ивановского. В своих мемуарах он рассказал, что внутренним рецензентом рукописи была Ахматова, написавшая об Ивановском: «Переводчик с большим вкусом», «...переводы <...> представляют собой большие достижения всей переводческой школы нашего времени», «...воспринимаются как природные русские стихи». «А в начале следующего года, - продолжил Ивановский, — я получил от нее в подарок книгу стихотворений, вышедшую в Гослитиздате. На титульном листе была надпись: “Милому Игнатию Михайловичу Ивановскому, самому лучшему переводчику”» (Ивановский, 2006: 141).

В 1985 г. в журнале «Нева» впервые были напечатаны статья Ивановского «Совсем другой Шекспир» и несколько сонетов в его переводе. В 1994 г. появились переводы полного корпуса шекспировских сонетов, переизданные в 2001 г. (Шекспир, 2001). Ивановский посвятил эту работу памяти М. $\Lambda$. Аозинского. «Посвящать переводы у нас не принято, - сказал переводчик, - но я сделал это, потому что в переводах сонетов мне удалось, больше, чем в других переводах, приблизиться к переводческим принципам Иозинского» (Ивановский, 2005: 155-156). У своего учителя Ивановский ценил его скрупулезное следование подлиннику. Аозинский считал оригинальный текст «духовным завещанием ушедшего из жизни поэта, а себя - его душеприказчиком. Ауховное завещание следует исполнить в точности», «насколько это позволяет достоинство русского стиха» (там же: 151). Поэтому Аозинский всегда совершал серьезное исследовательское погружение в эпоху, творческую биографию переводимого автора, своеобразие его художественной стилистики. Маршак, по мнению Ивановского, другой: мастер четко организованного стиха, он легко отступал от подлинника ради гармонической красоты перевода. «Читаю перевод Маршака, - признается Ивановский, - и кажется, что страница светится ровным ярким светом. Но беру подлинник и вижу, что световая палитра в нем совсем другая. Там есть и тени» (там же).

Творческие уроки Аозинского помогли Ивановскому открыть строптивую хаотичность и драматическую противоречивость «неудержимых», по его определению, шекспировских стихов. В результате переводчик услышал особые авторские откровения 
первых семнадцати стихотворений. Сонеты создавались с 1592 по 1598 г., а в 1596 г., напомнил переводчик, умер сын Шекспира Гамнет. Ивановский представил, какую страшную трагедию пережил писатель и какой выход из этой поистине философской катастрофы он мог найти: «У близкого по духу и прекрасного по физической природе человека должен родиться сын!» (там же: 154). Именно эта переводческая гипотеза дала Ивановскому возможность понять, как «совсем по-другому должна зазвучать и музыка первых семнадцати сонетов. Говоря музыкальными терминами, это вовсе не dolce (нежно, сладостно), к которому нас приучили переводчики, а скореe ostinato (неотступно), доходящее до furioso (страстно) и даже грозного imperioso (повелительно, властно) всего оркестра» (там же).

Именно так звучит у Ивановского его перевод самого «музыкального» сонета из первых семнадцати - 8-го:

Ты - музыка, но с музыкой в разладе,
А радость с радостью живет в ладу.
Так почему ты рад своей досаде
И любишь то, в чем чувствуешь беду?
Ведь это звук, со звуком обручен,
Аишь потому твой оскорбляет слух,
Что каждый миг напоминает он,
Как в одиночестве беднеет дух.
Послушай, как игрой неторопливой
Многоголосье струны создают.
Так сын с отцом и матерью счастливой
В тройном единстве слаженно поют.
Они без слов дают тебе упрек:
Немного проку в том, кто одинок

(Шекспир, 2001: 8).

В первой же строке здесь явно ощутима напряженность шекспировского контрапункта ("Music to bear, why bear'st thou music sadly?"), явно смягченного у Маршака ( "Ть - музыка, но звукам музькальным / Ть внемлешь с непонятною тоской»). Ивановскому удается воспроизвести и удивительный шекспировский образ звуков, вступающих в брачный союз ("sounds, / By unions married”) ) - образ, приобретающий силу сюжетообразующего мотива. Не случайно финальное imperioso у Ивановского поют "сын с отиом и матерью счастливой», а не неопределенное "согласье струн в конщерте », как у Маршака. Поэтический контекст переводного сонета Ивановского - это настроение нарастающей тревоги («чувствуешь беду», «каждый миг напоминает он / Как в одиночестве беднеет Аух», «тебе упрек»), и завершающий призыв стихотворения приобретает в этом контексте особый драматизм.

Во всех семнадцати сонетах напоминания о разрушительном времени и о трагедии одиночества, от которой Поэт предостерегает Аруга, у Ивановского насыщенно экспрессивны и создают в его образной палитре те самые тревожные тени, которых действительно нет у Маршака. Так, в переводе 6-го сонета у Маршака читаем: «Смотри же, чтобы жесткая рука / Седой зимы в саду не побыъала» (Шекспир, 1984: 44). Но переводческий окказионализм Ивановского делает поэтическую интонацию сонета более напряженной: «Так пусть же память лета не убьет / Зимь задубенелая рука» (Шекспир, 2001: 6). В 13-м сонете Маршак уверен в благополучном завершении событий, утверждая: «В заботливых руках прекрасный дом / Не дрогнет перед натиском 
зимь, / И никогда не воиарится в нем / Аьханье смерти, холода и тьмь» (Шекспир, 1984: 52). Однако Ивановский не уверен в нем, вполне предполагая возможность трагического финала: «Неужто рухнет столь прекрасный кров, / Которьй зимним дням наперекор, / Сдержал бы натиск ледяных ветров / И смертной стужи вьнес бь напор?" (Шекспир, 2001: 8). Ааже сами выражения угрозы у Маршака достаточно спокойны - «время нам грозит осадой» (16-й сонет) (Шекспир, 1984: 55). Но Ивановский взрывает этот покой: «точит нож / Кровавый деспот Время, враг живых" (Шекспир, 2001: 16). Особенно впечатляет жесткий вариант его заключительного дистиха 1-го сонета. "Так сжальсл! Нашу радость, гордость, честь / Ты и могила - вь хотите съесть" (Шекспир, 2001: 1). Шекспировское "Pity the world, or else this glutton be, / To eat the world's due, by the grave and thee" Маршак перевел более мягким и к тому же образно далеким от оригинала выражением: «Жалея мир, земле не предавай / Грядущих лет прекрасньй урожай! » (Шекспир, 1984: 39).

Важно знать, что шекспировские сонеты для Ивановского «ни в чем не напоминают целостно задуманного литературного произведения», в них нет «ни общего замысла, ни композиции. Это нечто среднее между дневником и пачкой писем» (Ивановский, 2005: 153-154). Соответственно, первые 17 стихотворений в его понимании отдельная маленькая составляющая в этой перечислительной «пачке» не связанных воедино посланий.

\section{ТРАКТОВКА И. З. ФРАДКИНА}

Аругой не менее известный петербургский автор - поэт-переводчик Игорь Залманович Фрадкин иначе увидел структурно-функциональную роль первых семнадцати сонетов в шекспировском цикле. Переводчик А. Китса, О. Уайльда, Г. Аонгфелло, Р. Фроста и других англоязычных авторов, Фрадкин довольно долго работал над своей версией полного сонетного корпуса Шекспира. Ее первый вариант был опубликован в 1990 г., в 2003 г. появилась обновленная авторская редакция этих переводов (Шекспир, 2003). Издатели справедливо указали на богатый опыт и высокое переводческое мастерство Фрадкина, присущее ему тонкое ощущение поэтического текста, уважительное отношение к подлиннику, бо́льшую по сравнению с Маршаком точность в передаче смысла и стиля стихов Шекспира. Фрадкину действительно удалось найти свое переводческое прочтение «Сонетов». Так, в отличие от Ивановского, полагавшего, что в целом шекспировские стихи не являются единым циклом, Фрадкин твердо убежден в их композиционном и поэтическом единстве.

Уверенность переводчика в художественной целостности шекспировского сонетного свода просматривается уже в эдиционно-редакторском структурировании последнего издания его сонетных переводов. В известной мере на эту целостность указывает наличие своеобразного аннотирующего эпиграфа, предваряющего цикл. Его роль выполняет 144-й сонет, который воспроизводится не только на своем обычном месте между 143-м и 145-м, но еще и дополнительно в начале сборника.

Но самое удивительное в этом редакторском решении - то, что из собрания шекспировских сонетов Фрадкин строит - ...сонет! Точнее говоря, развернутую сонетную композицию. Формально она аранжирована рамочной конструкцией заголовков, самостоятельно введенных переводчиком. Весь свод разбит у него на семь частей, каждая из которых имеет свое двуязычное название, дополненное двухстрочным эпиграфом, взятым из сонетов в переводе Фрадкина. В результате все вместе эти цитаты составляют те самые «14 магических строк» (см. табл., с. 288). 
РАМОЧНАЯ КОНСТРУКЦИЯ И. З. ФРААКИНА

Таблица

Table

I. Z. FRADKIN'S FRAME CONSTRUCTION

\begin{tabular}{|c|c|c|c|c|}
\hline Yacms & Сонеть & \multicolumn{2}{|c|}{ Заглавие } & Эnuгpaф \\
\hline I & $1-17$ & $\begin{array}{l}\text { One is no } \\
\text { number }\end{array}$ & Один - ничто & $\begin{array}{l}\text { Мир отощает - мщенья час придет: } \\
\text { Пожрет в могиле Мир тебя и плод. } \\
(1-и ̆ \text { сонет, 13-я и 14-я строки) }\end{array}$ \\
\hline II & $18-32$ & Friendship's sun & $\begin{array}{l}\text { Солнце } \\
\text { Аружбы }\end{array}$ & $\begin{array}{l}\text { Могу ль тебя равнять я с летним днем? } \\
\text { Ты и желанней и милей рассвета... } \\
\text { (18-й сонет, 1-я и 2-я строки) }\end{array}$ \\
\hline III & $33-55$ & $\begin{array}{l}\text { Friendship's } \\
\text { faces }\end{array}$ & Аики Аружбы & $\begin{array}{l}\text { Несущего тяжелый крест обид } \\
\text { Не трогают слова пустой печали } \\
(34-и ̆ \text { сонет, 11-я и 12-я строки) }\end{array}$ \\
\hline IV & $56-76$ & Cruel time & Крутое время & 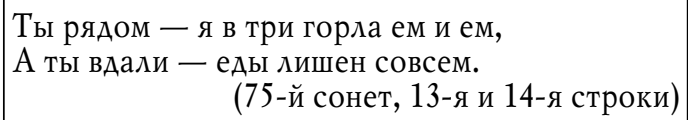 \\
\hline V & $76-96$ & Jealousy & Ревность & $\begin{array}{l}\text { Когда другому полнишь парус строф, } \\
\text { То виснет парус мой, дишенный слов. } \\
(86-и ̆ \text { сонет, } 13-я \text { и } 14-я \text { строки })\end{array}$ \\
\hline VI & $97-126$ & $\begin{array}{l}\text { Hymn } \\
\text { to Friendship }\end{array}$ & Гимн Аружбе & $\begin{array}{l}\text { Я на перо нанизываю строки, } \\
\text { Тщась диво дивное изобразить. } \\
\text { (103-й сонет, 11-я и 12-я строки) }\end{array}$ \\
\hline VII & $127-154$ & Fleshly love & Земная любовь & 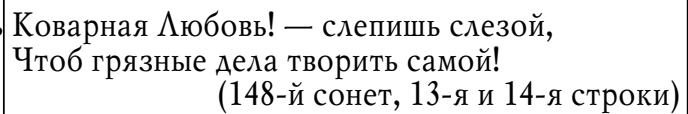 \\
\hline
\end{tabular}

Однако главным образом единство шекспировского сборника предстает у Фрадкина не в формальной, а в поэтической организации цикла, центростремительной силой которого переводчик видит идею духовной победы над разрушительным Временем. Эта магистральная художественная позиция придает серьезный содержательный смысл некоторым эдиционным находкам Фрадкина. Очевидно, что в построенной им «сонетной» композиции первым семнадцати стихотворениям отведена экспозиционная роль своеобразного зачина, где обычно формулируется тематическая заставка сонетного тезиса. Именно здесь зарождаются у Фрадкина циклообразующие и концептуально важные поэтические лейтмотивы Смерти и Возрождения. Они начинают звучать уже в 1-м сонете:

От дивного ждем дивных всходов мы,

Ведь роза красоты в час неизбежный

Погибнет, и спасти от вечной тьмы

Ее способен только отпрыск нежный.

Но, с ясным своим ликом обручен,

Своим богатством ты пренебрегаешь 
И на пиру, на голод обречен,

От собственного пламени сгораешь.

Весны прекрасный вестник! - от огня

Ты скрягой гибнешь: словно бы во злобе

Свет красоты лишаешь, хороня

Зародыш дивный в собственной утробе.

Мир отощает - мщенья час придет:

Пожрет в могиле Мир тебя и плод

(Шекспир, 2003: 13).

Известно, что в соответствии с поэтическими законами сонета разворачивание его главной темы, заявленной в начальным тезисе, получит соответствующее разрешение в завершающем сонетном замке, где особенно сильно и ярко должна прозвучать авторская идея произведения. В «сонетной» конструкции Фрадкина роль этой завершающей позиции отведена ключевому, по его мнению, 146-му сонету, содержащему философское кредо Шекспира:

\footnotetext{
Мой бедный Аух, греховной плоти суть,

Ты не способен выдержать осаду

Мятежных сил - нельзя жить как-нибудь,

Ааря все краски одному фасаду.

Зачем, на срок взяв этот дом внаем,

Фасад усердно красишь то и дело?

Чтоб черви пировали пышно в нем,

Когда ты бренное покинешь тело?

Знай: тело - раб; сокровища копи,

За счет раба живи, Смерть объедая,

Божественную будущность скупи,

Иетящие в ничто дни продавая.

Ту Смерть, что жрет людей, сам поглоти:

Пожрав ее, бессмертье обрети
}

(Шекспир, 2003: 179).

«Если в 1-м сонете, - считает переводчик, - Поэт напоминает другу, что возрождение после смерти невозможно без продления рода, ибо отощавший мир набросится и пожрет в могиле останки друга вместе с неродившимся сыном, то в 146-м сонете воспевается волшебная способность творчества морить Смерть голодом и сживать ее со света, обретая таким образом собственное бессмертие и оставаясь в памяти человечества» (Фрадкин, 2003: 202). Поэтому так отчетлива у Фрадкина поэтическая перекличка финальных дистихов 1-го и 146-го сонетов.

Как видим, трактовка Фрадкина позволяет открыть новые грани циклообразующего потенциала шекспировского сборника. В этом плане чрезвычайно интересно обратить внимание на то, что это переводческое решение подтверждает исследовательскую гипотезу видного отечественного шекспироведа А. Н. Горбунова. По его предположению, 146-й сонет, который по глубине идейных мотивов целиком отвечает поэтическим правилам средневековых и ренессансных эпилогов, вполне мог завершать сонетный свод Шекспира (Горбунов, 2008: 24).

СТИАИЗОВАННЫЕ ПЕРЕВОАЧЕСКИЕ ВАРИАЦИИ Ю. И. АИФШИЦА

Особая обновляющая энергетика воплощена в имитативных переводческих вариациях на темы шекспировских сонетов. Уточним: речь идет не просто о шекспировских 
реминисценциях в оригинальных стихах переводчиков, а именно о поэтических фантазиях, рождаемых на основе и в процессе переводческого поиска. Подобные фантазии - результат высочайшей политекстуальности шекспировских стихов и их замечательной открытости перспективам бесконечных смысловых преображений. Конечно, серьезным побуждающим фактором стали и характерные тенденции постмодернистских «текстов без берегов», размывающих жанровые границы. В результате возникла возможность удивительной творческой игры художественными смыслами шекспировских стихов, побуждающих к новыми и неожиданным образным находкам.

Показателен опыт Юрия Иосифовича Аифшица. Тонко почувствовавший в стихотворениях Шекспира динамическую экспрессию диалога, который ведут герои его сонетного цикла, он поначалу воплотил это ощущение не в переводах, а в оригинальном творческом эксперименте, смело преобразовав сонеты Шекспира в стилизованные монологи, написанные в обычном для шекспировских пьес разностопном нерифмованном ямбе. В монологах, написанных на основе первых 17 сонетов, у Аифшица неожиданно зазвучал голос хотя и совершенно нового персонажа, но родственного по духу шекспировским героям, - одержимой страстью женщины, не желающей мириться с тем,

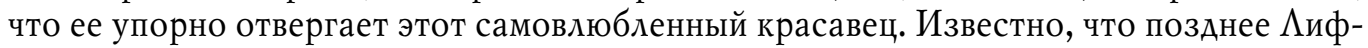
шиц выполнил перевод полного цикла сонетов, полностью выдержав строгий сонет-

\begin{tabular}{|c|c|}
\hline $\begin{array}{c}\text { Ю. И. Аифшищ: } \\
\text { монолог-Вариачия на основе 1-го сонета }\end{array}$ & $\begin{array}{l}\text { Ю. И. Аифиши: } \\
\text { перевод 1-го сонета }\end{array}$ \\
\hline $\begin{array}{l}\text { Мы страстно жаждем, чтобы умножалось } \\
\text { Все что ни есть прекрасного на свете. } \\
\text { Пусть роза - воплощенье красоты, - } \\
\text { Завянет, распуститься не успев, } \\
\text { Но в памяти потомства своего, } \\
\text { В его бутонах нежных возродится. } \\
\text { Но ты в свои лучистые глаза } \\
\text { Глядишь и глаз не можешь отвести, } \\
\text { Помолвлен с отражением зеркальным. } \\
\text { Сгораешь ты на медленном огне, } \\
\text { В костер бросаешь собственную сущность, } \\
\text { Хотя, глодая самого себя, } \\
\text { Ты голодаешь, сидя на пиру, } \\
\text { И ненавидишь до смерти себя, } \\
\text { Желая смерти юности своей. } \\
\text { Ты ныне освежаешь, украшая, } \\
\text { Весь этот мир; не кто иной, как ты, } \\
\text { Весны предвозвещаешь торжество } \\
\text { И в то же время губишь на корню } \\
\text { В себе самом начало новой жизни, } \\
\text { Хоронишь содержание свое, } \\
\text { Тем самым, юный скряга, совмещая } \\
\text { В одном лице и мота, и скупца. } \\
\text { Жалея мир, смири свой аппетит, } \\
\text { Не то твоя проглотит ненасытность } \\
\text { Не что-нибудь, а достоянье мира } \\
\text { Аа и тебя навек загонит в гроб. }\end{array}$ & $\begin{array}{l}\text { Пусть только наилучшее растет! } \\
\text { И не погибнет роза красоты, } \\
\text { Когда цветы умрут, но в свой черед } \\
\text { Их обессмертят юные цветы. } \\
\text { А ты, влюбленный в собственную стать, } \\
\text { Горишь самоубийственным огнем, } \\
\text { В пиру предпочитаешь голодать, } \\
\text { Чтоб жертвой стать себе и палачом. } \\
\text { В тебе - весь мир, ты - юности венец, } \\
\text { Весны герольд, но свой богатый клад } \\
\text { В себе ты прячешь, милый мой скупец, } \\
\text { И в то же время тратишь невпопад. } \\
\text { Не ешь того, что всем принадлежит, } \\
\text { Не то тебя убьет твой аппетит. }\end{array}$ \\
\hline
\end{tabular}


ный канон Шекспира (Шекспир, 2006). Но и здесь вполне реально ощущалась та настойчивая героиня, которую он нашел в своих переводческих предчувствованиях.

\section{ЗАКАЮЧЕНИЕ}

Окончательный итог сказанному подводить еще рано. Представленные наблюдения необходимо расширить и продолжить. Отдельного внимания, к примеру, требует переводческий и исследовательский опыт Я. М. Колкера (Колкер, 2014). Однако уже сейчас нам представляется важным говорить не только о множестве и разнообразии переводческих подходов к шекспировским сонетам, но и о замечательном явлении «русской» сонетианы «русского» Шекспира. Этот переводческий феномен в особенной мере позволяет судить о принципиальном своеобразии переводной литературы, наделенной удивительной креативной устремленностью к возрастающей множественности творческих решений.

\section{СПИСОК АИТЕРАТУРЫ}

Аникст, А. А. (1963) Творчество Шекспира. М. : ИзА-во художественной дитературы. 615 с. Аникст, А. А. (1984) Комментарии // Шекспир У. Сонеты. М. : Радуга. 368 с. С. 293-362.

Горбунов, А. Н. (2008) 146-й сонет Шекспира и его место в цикле // Шекспировские штудии X : Шекспировские чтения 2008. Мат. Международной. науч. конф. (Москва, 29 сентября 3 октября 2008 года) / отв. ред. Н. В. Захаров, Вл. А. Иуков. М. : Изд-во Моск. гуманит. ун-та. 90 c. C. $15-24$.

Ивановский, И. М. (2005) Фрагменты (из книги «Почтовая лошадь») // Зарубежные записки. Журнал русской литературы. Книга IV. С. 149-157.

Ивановский, И. М. (2006) Фрагменты (из книги «Почтовая лошадь») // Зарубежные записки. Журнал русской литературы. Книга VII. С. 137-145.

Колкер, Я. М. (2014) Поэзия и проза художественного перевода. М. : Гуманитарий. 497 с.

Ауков, Вл. А., Флорова, В. С. (2009) «Сонеты» Уильяма Шекспира: от контекстов к тексту (К 400-летию со дня публикации шекспировских «Сонетов») : монография. Аля обсуждения на научном семинаре 23 апреля 2009 года / отв. ред. Н. В. Захаров; Моск. гуманит. ун-т. Ин-т фундамент. и прикл. исследований; Межд. акад. наук (IAS). М. : Изд-во Моск. гуманит. ун-та. 94 с.

Морозов, М. М. (1954) Избранные статьи и переводы. М. : Гос. изд-во художественной литературы. 596 с.

Фрадкин, И. 3. (2003) Аружба, Аюбовь и Время в Сонетах Шекспира // Шекспир У. Сонеты / пер. с англ. И. 3. Фрадкина. СПб. : АЕАН. 207 с. С. 190-203.

Шекспир, У. (1984) Сонеты. М. : Радуга. 368 с.

Шекспир, В. (2001) Сонеты / пер. И. М. Ивановского. СПб. : ТЕССА. 320 с.

Шекспир, У. (2003) Сонеты / пер. И. 3. Фрадкина. СПб. : АЕАН. 207 с.

Шекспир, У. (2006) Сонеты / пер. Ю. И. Иифшица. Екатеринбург : Изд-во Урал. ун-та. 176 с.

Shake-speares sonnets: Neuer before imprinted. (1609) At London : By G. Eld for T[homas] $\mathrm{T}$ [horpe] and are to be solde by Iohn Wright, dwelling at Christ Church gate.

Дата поступления: 6.09.2015 2.

WHY THE POET'S FRIEND SHOULD MARRY:

RUSSIAN TRANSLATORS' INTERPRETATIONS OF THE FIRST 17 SHAKESPEARE'S SONNETS

E. A. Pervishina

(FAR EASTERN FEDERAL UNIVERSITY, VLADIVOSTOK)

The first 17 sonnets in Shakespeare's cycle - the ones where the speaker is admiring his handsome Friend and trying to persuade him to get married - have always attracted readers' attention. In recent decades, when the amount of synchronic interpretations in Russia has remarkably increased, 
translators' interpretations of these 17 poems have intensified as well. The purpose of the article is to present the most significant and interesting among these interpretations.

Ignatii Ivanovskii, one of the best representatives of Russian school of poetic translation, has noticed that the first 17 sonnets may have reflected the dreadful personal tragedy - the death of Shakespeare's son, Hamnet, in 1596. That is why in Ivanovskii's version the "poetic music" of these sonnets sounds highly expressive and alarming.

Igor Fradkin, another well-known poet and translator, is convinced of compositional and poetic integrity of Shakespeare's sonnet collection. This conviction is conspicuous even in the structure of the latest edition of Fradkin's translations, which has been arranged according to the principles of extensive sonnet composition. The first 17 poems introduce and formulate the sonnet thesis. It is here, according to Fradkin, that the core motifs of Death and Revival originate, which give shape to the whole collection.

Imitative variations of Shakespeare's sonnets have a peculiar creative energy of their own. By setting up new projections, they disclose the potential of freely playing with Shakespearean themes. Thus, while perceiving the dialogue expressiveness in Shakespeare's poems, Yuri Lifshits in his poetic variations created a new female character - the woman obsessed with her passion to a young handsome man.

The translators' interpretations are therefore very important in the receptive creation of a poetic image of the Russian Shakespeare.

Keywords: Shakespeare; Shakespeare's sonnets; Russian translations of Shakespeare's sonnets

\section{REFERENCES}

Anikst, A. A. (1963) Tvorchestvo Shekspira [Shakespeare's creative work]. Moscow, Izdatel'stvo khudozhestvennoi literatury [Publishing of Fiction Literature]. 615 p. (In Russ.).

Anikst, A. A. (1984) Kommentarii [Commentary]. In: Shakespeare, W. Sonety [Sonnets]. Moscow, Raduga Publ. 368 p. Pp. 293-362. (In Russ.).

Gorbunov, A. N. (2008) 146 sonet Shekspira i ego mesto v tsikle [Shakespeare's Sonnet 146 and its place within the cycle]. In: Shekspirovskie shtudii X: Shekspirovskie chteniia 2008 [Shakespeare Studies X: Shakespeare Readings 2008] : Proceedings of the International Conference (Moscow, September 29 - October 3, 2008) / ed. by N. V. Zakharov and Vl. A. Lukov. Moscow, Moscow University for the Humanities Press. 90 p. Pp. 15-24. (In Russ.).

Ivanovskii, I. M. (2005) Fragmenty (iz knigi «Pochtovaia loshad'») [Excerpts from “The Post Horse"]. Zarubezhnye zapiski. Zhurnal russkoi literatury, bk. IV, pp. 149-157. (In Russ.).

Ivanovskiy, I. M. (2006) Fragmenty (iz knigi «Pochtovaia loshad'») [Excerpts from "The Post Horse"]. Zarubezhnyie zapiski. Zhurnal russkoi literatury, bk. VII, pp. 137-145. (In Russ.).

Kolker, Ya. M. (2014) Poeziia i proza kbudozhestvennogo perevoda [The poetry and the prose of literary translation]. Moscow, Gumanitarii Publ. 497 p.

Lukov, Vl. A. and Florova, V. S. (2009) "Sonety» Shekspira: ot kontekstov k tekstu (K 400-letiiu so dnia publikatsii shekspirovskikb «Sonetov") [Shakespeare's "Sonnets": From the contexts to the text (To the 400th anniversary of the publication of Shakespeare's "Sonnets"] : Monograph / ed. by N. V. Zakharov. Moscow, Moscow University for the Humanities Publ. 94 p. (In Russ.).

Morozov, M. M. (1954) Izbrannye stat' $i$ i perevody [Selected articles and translations]. Moscow, Gosudarstvennoe izdatel'stvo khudozhestvennoi literatury [State Publ. of Fiction Literature]. 596 p. (In Russ.).

Fradkin, I. Z. (2003) Druzhba, liubov' i vremia v sonetakh Shekspira [Friendship, love and time in Shakespeare's sonnets]. In: Shakespeare, W. Sonety [Sonnets]/ transl. by I. Z. Fradkin. St. Petersburg, DEAN Publ. Pp. 190-203. (In Russ.).

Shakespeare, W. (1984) Sonety [Sonnets]. Moscow, Raduga Publ. 368 p. (In Russ.).

Shakespeare, W. (2001) Sonety [Sonnets]/ transl. by I. M. Ivanovskii. St. Petersburg, TESSA Publ. 320 p. (In Russ.).

Shakespeare, W. (2003) Sonety [Sonnets] / transl. by I. Z. Fradkin. St. Petersburg, DEAN Publ. 207 p. (In Russ.). 
Shakespeare, W. (2006) Sonety [Sonnets] / transl. by Yu. I. Lifshits. Yekaterinburg, Ural Publ. 176 p. (In Russ.).

Shake-speares sonnets: Neuer before imprinted. (1609) At London : By G. Eld for T[homas] $\mathrm{T}$ [horpe] and are to be solde by Iohn Wright, dwelling at Christ Church gate.

Submission date: 6.09.2015.

Первушина Елена Александровна - доктор филологических наук, доцент, профессор Восточного института - Школы региональных и международных исследований Аальневосточного федерального университета, почетный работник высшего профессионального образования. Адрес: 690950, Россия, г. Владивосток, ул. Суханова, д. 8. Тел.: +7 (423) 265-24-29; +7 (423) 243-34-72. Эл. aspec: pervushelena@yandex.ru

Pervushina Elena Aleksandrovna, Doctor of Philology, Professor, Institute of Oriental Studies School of Regional and International Studies, Far Eastern Federal University, Honoured worker of higher vocational education. Postal address: 8 Sukhanova St., 690950 Vladivostok, Russian Federation. Tel.: +7 (423) 265-24-29; +7 (423) 243-34-72. E-mail: pervushelena@yandex.ru 